Disponível em

http://www.anpad.org.br/rac

RAC, Rio de Janeiro, v. 18, n. 2, art. 5, pp. 196-216, Mar./Abr. 2014

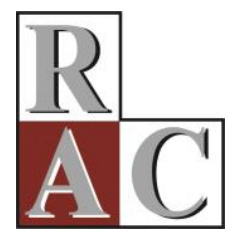

\title{
Alerta Empreendedor e as Abordagens Causation e Effectuation sobre Empreendedorismo
}

\section{Entrepreneurial Alertness and the Causation and Effectuation Approaches to Entrepreneurship}

Valter da Silva Faia

E-mail: valterfaia@gmail.com Universidade Estadual de Maringá - UEM PPA/UEM, Av. Colombo, 5790, Bloco C23, sala 15, 87020-900, Maringá, PR, Brasil.

Marco Aurélio Garcia Rosa E-mail: marcogarcia81@ hotmail.com Universidade Estadual de Maringá - UEM PPA/UEM, Av. Colombo, 5790, Bloco C23, sala 15, 87020-900, Maringá, PR, Brasil.

Hilka Pelizza Vier Machado

E-mail: hilkavier@yahoo.com

Universidade Estadual de Maringá - UEM PPA/UEM, Av. Colombo, 5790, Bloco C23, sala 15, 87020-900, Maringá, PR, Brasil. 


\title{
Resumo
}

Segundo Gartner (1985), entender as dimensões e as variáveis acerca do empreendedorismo e como essas se relacionam contribui para a compreensão do fenômeno de criação de novos empreendimentos. O alerta empreendedor (Kirzner, 1997) explica como oportunidades de negócios são identificadas, e contribui para a criação de novas empresas. Este trabalho objetivou relacionar o grau de alerta empreendedor com as abordagens empreendedoras causation, embasada no planejamento e na análise, e effectuation, referente à exploração de oportunidades emergentes de forma não preditiva, ambas apresentadas por Sarasvathy (2001). Como objetivo específico, pretendeu validar a escala de alerta empreendedor desenvolvida por Tang, Kacmar e Busenitz (2012), e as escalas das abordagens mencionadas anteriormente e desenvolvidas por Chandler, Detienne, Mckelvie e Mumford (2011). A pesquisa foi realizada junto a uma amostra de 123 empresários de diversos setores, participantes de associações comerciais. As escalas foram validadas em termos de confiabilidade e multidimensionalidade. Ademais, os resultados demonstram uma relação positiva entre alerta empreendedor e as abordagens empreendedoras, especialmente para a abordagem causation. Identificou-se também uma relação não linear quadrática entre o nível de alerta e a abordagem causation, indicando um ponto médio em que a relação positiva se inverte.

Palavras-chave: alerta empreendedor; causation; effectuation.

\begin{abstract}
According to Gartner (1985), to understand the dimensions and variables of entrepreneurship and how they relate to each other contributes to understanding the phenomenon of new venturing creation. Entrepreneurial alertness (Kirzner, 1997) explains how business opportunities are identified and contributes to the creation of new business. This study aimed to relate the level of entrepreneurial alertness to entrepreneurial approaches causation, consistent with the concept of planning and analysis, and effectuation, consistent with the exploitation of emerging opportunities in a non-predictive way, both presented by Sarasvathy (2001). As a specific objective, it intended to validate the entrepreneurial alertness scales developed by Tang, Kacmar and Busenitz (2012), and entrepreneurial approaches scales, developed by Chandler, Detienne, Mckelvie and Mumford (2011). The survey was realized with a sample of 123 entrepreneurs from various sectors who were participants of business associations. The scales were validated in terms of reliability and multidimensionality. The results present a positive relationship between entrepreneurial alertness and entrepreneurial approaches, especially in terms of causation. A quadratic nonlinear model was also identified in this relationship, indicating a middle point in which the relationship becomes reversed.
\end{abstract}

Key words: entrepreneurial alertness; causation; effectuation. 


\section{Introdução}

A importância atual do empreendedorismo e do capital empreendedor é ressaltada por autores como Aidar (2007), Filion (1999), Schramm e Litan (2008), entre outros. Os empreendedores estão superando barreiras comerciais e culturais, encurtando distâncias, globalizando e renovando os conceitos econômicos, criando novas relações de trabalho e novos empregos, quebrando paradigmas e gerando riqueza para a sociedade (Filion, 1999).

Gartner (1985), ao discutir a criação de novos empreendimentos, apresentou um modelo multidimensional composto por quatro dimensões: indivíduo - pessoa envolvida na criação de um novo empreendimento; organização - tipo de firma iniciada; ambiente - a situação e o contexto que influencia o novo empreendimento; e processo - as ações realizadas pelos indivíduos. Para Gartner (1985), entender o fenômeno da criação de novos empreendimentos significa realizar uma investigação a partir dessas quatro dimensões, na tentativa de identificar quais variáveis impactaram no sucesso ou no fracasso, bem como como as variáveis das distintas dimensões interagem entre si.

Dessa forma, o presente estudo discute, especificamente, sobre variáveis referentes às dimensões indivíduo e processo. Na dimensão indivíduo, será dado enfoque à descoberta, à avaliação e à exploração de oportunidades. Assim, a busca deliberada por informações, a capacidade cognitiva para associá-las e esquematizá-las, e a capacidade de avaliar as melhores oportunidades dentre tantas, constituem características importantes para um empreendedor. Esses elementos são conceituados por Tang, Kacmar e Busenitz (2012) como um estado de alerta empreendedor do indivíduo para se engajar em um novo empreendimento. Sobre o processo empreendedor, destaca-se o estudo desenvolvido por Sarasvathy (2001), o qual apresenta duas abordagens distintas: causation, consistente com o conceito de planejamento e análise, e effectuation, referente à exploração de oportunidades emergentes de forma não preditiva.

Sendo assim, o objetivo desta pesquisa foi relacionar o grau de alerta empreendedor com as abordagens empreendedoras causation e effectuation, procurando observar o grau de predição do nível de alerta para essas abordagens. Como objetivo específico, buscou-se validar as escalas de alerta empreendedor e de abordagens causation e effectuation, desenvolvidas por Tang et al. (2012) e Chandler, Detienne, Mckelvie e Mumford (2011), respectivamente. Com isso, procura-se contribuir para a compreensão de como indivíduos identificam oportunidades, por meio do alerta, e como eles as exploram, por meio das abordagens causation ou effectuation, bem como verificar a relação entre a identificação (alerta) e o modo de exploração de oportunidades (causation e effectuation).

O artigo está estruturado, inicialmente, com a apresentação dos conceitos de alerta empreendedor e das abordagens empreendedoras. Posteriormente, são mencionados os procedimentos adotados para coleta e análise dos dados, bem como o tipo de pesquisa realizada. Os resultados são evidenciados por meio das técnicas estatísticas análise fatorial, teste de confiabilidade, correlação e regressão. Por fim, são apresentadas as discussões e as interpretações dos resultados, bem como as contribuições, as limitações e as sugestões de pesquisas futuras.

\section{Considerações Sobre Alerta Empreendedor}

Um importante aspecto do processo empreendedor refere-se à identificação de uma oportunidade de negócio por um indivíduo (Gartner, 1985). Shane e Venkataraman (2000) tratam das oportunidades como sendo as situações em que novos bens, serviços, matérias-primas e métodos podem ser introduzidos e vendidos a um preço superior aos seus custos. Os autores estabelecem um nexo entre indivíduos e oportunidades, destacando a importância de estudos relacionados às fontes das oportunidades; aos processos de descoberta, avaliação e exploração destas pelos indivíduos; bem como aos fatores que levam alguns indivíduos, e outros não, a descobrirem-nas. 
Para Shane e Venkataraman (2000), é importante compreender porque alguns indivíduos e não todos descobrem oportunidades. Segundo os autores, isso ocorre pela existência de erros e falhas nos mercados na fixação de preços, permitindo a compra de recursos com preços baixos, recombinando-os e revendendo-os em mercados nos quais os preços estejam maiores. Em segundo lugar, destacam o constante estado de desequilíbrio do mercado, defendido por Joseph Schumpeter, no qual a informação é distribuída de forma imperfeita, e o estágio de equilíbrio se dá por meio do sistema de preços. Sendo assim, alguns indivíduos, ao tomarem posse dessas informações antes de outros, da mesma forma, podem adquirir recursos com preços menores, revendendo-os após a recombinação. A esse desequilíbrio, a abordagem econômica denomina assimetria de informações (Kirzner, 1997).

Dessa forma, um aspecto importante na relação indivíduo-oportunidade refere-se ao reconhecimento de oportunidades por parte do indivíduo, o qual é definido por Baron (2010, p. 129): "como o processo pelo qual se interpreta a informação que nos é traduzida pelo nosso sentido, a qual se integra com informações já armazenadas na memória". Lumpkin e Lichtenstein (2005) definem o reconhecimento de uma oportunidade como uma habilidade para identificar uma boa ideia, transformando-a em um conceito de negócio, gerando valor e gerando receitas. Os autores avaliam a descoberta de oportunidade quanto ao seu nível de causalidade, podendo ser deliberadas (baixa causalidade) e não intencionais (alta causalidade).

Para Kirzner (1997), o empreendedor deve se manter em estado de procura constante por circunstâncias até então despercebidas no ambiente, que possam inspirar uma nova atividade. "Sem saber o que procurar, sem a implantação de qualquer técnica de busca deliberada, o empreendedor está sempre avaliando o horizonte como se estivesse pronto para realizar novas descobertas" (Kirzner, 1997, p. 72). Segundo Hébert e Link (2006), a essência do empreendedorismo é o alerta para oportunidades, sendo o papel do empreendedor alcançar um tipo de ajustamento necessário para o equilíbrio do mercado. O alerta empreendedor tem sido central no recente desenvolvimento da área de empreendedorismo. Ele é importante na compreensão sobre como surgem novas ideias, auxiliando alguns indivíduos a identificarem mudanças no ambiente e possibilidades negligenciadas por outros. $\mathrm{O}$ indivíduo em estado de alerta é semelhante a alguém que possui uma antena, o que lhe permite reconhecer as oportunidades mesmo com pistas limitadas (Tang, Kacmar, \& Busenitz, 2012). Assim, Ardichvili, Cardozo e Ray (2003, p. 113) definem alerta empreendedor como uma "propensão para perceber e ser sensível a informações sobre objetos, incidentes e padrões de comportamento no ambiente, com especial sensibilidade para os problemas de clientes e fornecedores, necessidades não atendidas e interesses e novas combinações de recursos".

Kaish e Gilard (1991) referem-se ao alerta empreendedor como sendo uma preparação única para o reconhecimento de oportunidades e para a ação. Entretanto, McMullen e Shepherd (2006) destacam a importância da ação, uma vez que o estado de alerta, por si só, não resulta em um empreendimento, na medida em que "ser um empreendedor, logicamente, implica que o alerta empreendedor foi exercido. Sem o alerta, o indivíduo não teria percebido e atuado na oportunidade, e não seria, portanto um empreendedor" (McMullen \& Shepherd, 2006, p. 145).

Shane e Venkataraman (2000) apontam para dois fatores importantes relacionados ao alerta empreendedor: a posse de informações prévias necessárias e as propriedades cognitivas necessárias para avaliá-las. Segundo os autores, os indivíduos possuem diferentes estoques de informação, que influenciam a habilidade deles para reconhecer oportunidades. Mas para reconhecerem uma oportunidade, os empreendedores devem ter uma informação prévia complementar à nova informação. Além disso, como mencionado anteriormente, a distribuição da informação é desigual, assimétrica, sendo que há pessoas que, por algumas circunstâncias, detém melhores informações ou as detém previamente. Entretanto, apenas com a posse da informação, sem a habilidade cognitiva para identificar novas relações entre meios e fins, a exploração da oportunidade pode falhar.

Sobre a capacidade cognitiva, Grégoire, Barr e Shepherd (2010) destacam a importância do alinhamento estrutural como base para o reconhecimento de oportunidades. Esse alinhamento refere-se à comparação entre objetos, gerando implicações, ou seja, os indivíduos, ao se depararem com um novo objeto, procuram imediatamente encontrar semelhanças com objetos que eles já conheçam. Essas 
similaridades e comparações são construídas para melhor compreensão do novo objeto e desempenham um papel importante na forma como as pessoas compreendem a nova informação, aprendem novos conceitos e desenvolvem novas categorias.

Para Tang et al. (2012), o alerta empreendedor contém três dimensões: varredura e procura por novas informações; associação e conexão; e avaliação e julgamento. A partir dessas dimensões, os autores propuseram e validaram uma escala composta por 13 itens, como mostra a Tabela 1:

Tabela 1

\section{Escala de Alerta Empreendedor}

\begin{tabular}{|c|c|}
\hline Dimensão & Itens \\
\hline \multirow{6}{*}{$\begin{array}{l}\text { Varredura e } \\
\text { Procura }\end{array}$} & Eu interajo frequentemente com os outros para adquirir novas informações. \\
\hline & Eu sempre estou de olho em novas ideias de negócios quando vejo alguma informação. \\
\hline & Eu leio jornais, revistas ou publicações regularmente para adquirir novas informações. \\
\hline & Eu navego na internet todos os dias à busca por informações. \\
\hline & Eu sou um ávido (insaciável) buscador de informações. \\
\hline & Eu estou sempre procurando ativamente novas informações. \\
\hline \multirow{3}{*}{$\begin{array}{l}\text { Associação e } \\
\text { Conexão }\end{array}$} & Eu vejo associações entre informações aparentemente não relacionadas. \\
\hline & $\begin{array}{l}\text { Eu sou bom em conectar pontos (descobrir oportunidades relacionando fatos aparentemente não } \\
\text { relacionados). }\end{array}$ \\
\hline & $\begin{array}{l}\text { Eu costumo ver conexões entre informações de vários domínios de conhecimento aparentemente } \\
\text { desconexos. }\end{array}$ \\
\hline \multirow{4}{*}{$\begin{array}{l}\text { Avaliação e } \\
\text { Julgamento }\end{array}$} & Eu tenho um instinto para encontrar oportunidades com potencial. \\
\hline & Eu consigo distinguir entre oportunidades lucrativas e oportunidades não tão lucrativas. \\
\hline & Eu tenho um talento para separar oportunidades de alto valor das oportunidades de baixo valor. \\
\hline & Ao se deparar com várias oportunidades, eu sou capaz de selecionar as boas. \\
\hline
\end{tabular}

Nota. Fonte: Tang, J., Kacmar, K. M., \& Busenitz, L. (2012). Entrepreneurial alertness in the pursuit of new opportunities (p. 84). Journal of Business Venturing, 27(1), 77-94. doi: 10.1016/j.jbusvent.2010.07.001

Este modelo de alerta empreendedor com as suas dimensões pode ser visualizado na Figura 1, que considera alguns inputs, como disposição, treinamento e experiência do indivíduo e redes de relacionamento; e alguns outputs, como atividades para a abertura do empreendimento ou novos resultados.

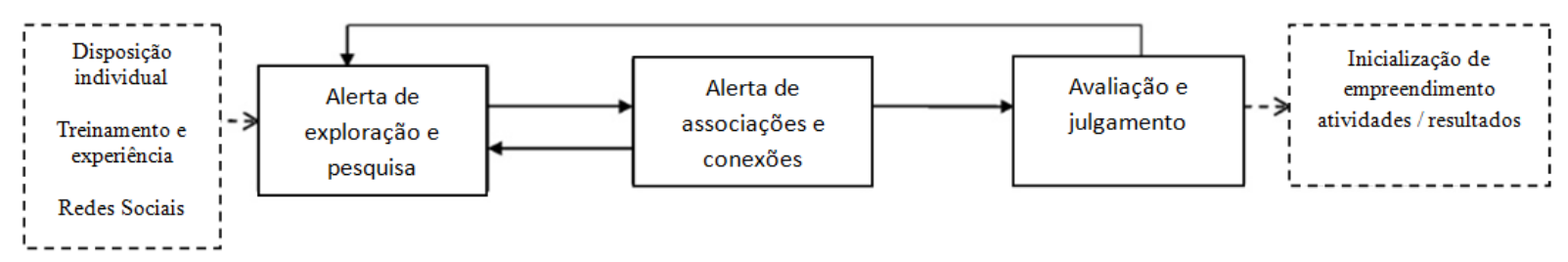

Figura 1. Modelo de Alerta Empreendedor.

Fonte: Tang, J., Kacmar, K. M., \& Busenitz, L. (2012). Entrepreneurial alertness in the pursuit of new opportunities (p. 80). Journal of Business Venturing, 27(1), 77-94. doi: 10.1016/j.jbusvent.2010.07.001

Inicialmente, o alerta ocorre pela busca constante por informações do ambiente negligenciadas por outros indivíduos (varredura e procura). Nesse ponto, é crucial a capacidade cognitiva no desenvolvimento de estruturas mentais, por meio do conhecimento prévio, da preparação e da sensibilidade para novas oportunidades. Envolve o conhecimento tácito, gerado pela experiência, e o 
explícito, advindo de fontes externas, os quais facilitam a integração e a acumulação de novos conhecimentos, como também a adaptação para novas situações (Tang et al., 2012).

A dimensão de associação e conexão consiste em unir diferentes peças da informação na construção de alternativas coerentes. Relaciona-se com a capacidade cognitiva do indivíduo em responder e processar as informações adquiridas. O indivíduo, na sua capacidade cognitiva, deve avaliar a relevância das informações coletadas, classificando as relevantes como positivas ou negativas. Posteriormente, cada evidência deve ser revisada, sendo confirmada ou não. Finalmente, as evidências mantidas são combinadas para posterior avaliação e julgamento. Feitas as associações, ele irá ou não retornar ao estágio de busca e pesquisa, como representado na Figura 1 (Tang et al., 2012).

A capacidade cognitiva de associações é descrita por Baron (2006, p. 106) como capacidade de "ligar os pontos". Para este autor, o reconhecimento de oportunidades depende de estruturas cognitivas dos indivíduos, consolidadas por meio de suas experiências de vida. Essas estruturas servem para organizar as informações armazenadas na memória em formas úteis, agindo como modelos ou padrões que permitem ao indivíduo perceber conexões entre mudanças e eventos aparentemente não relacionados. Como mencionado pelo autor, "em outras palavras, esses modelos oferecem a base cognitiva para 'conectar pontos' em padrões sugestivos para novas oportunidades de negócios" (Baron, 2006, p. 108).

Finalmente, os esquemas e as estruturas delineados cognitivamente são avaliados quanto ao seu potencial para uma oportunidade de negócio lucrativa, tanto por terceiros, quanto pelo próprio indivíduo. Possivelmente, essa avaliação pode requerer do indivíduo novas informações, para novas associações, novos ajustes ou reconsiderações de alternativas (Tang et al., 2012). Essa relação também pode ser observada na Figura 1. Do mesmo modo, Valliere (2013) salienta a importância do domínio cognitivo sobre o alerta empreendedor, favorecendo o reconhecimento de oportunidades em razão da forma como esses indivíduos capturam a representação de uma situação e da forma como eles mapeiam as mudanças ambientais, relacionando-as aos padrões mentais.

\section{Abordagens Empreendedoras - Causation e Effectuation}

$\mathrm{Na}$ medida em que o interesse em Empreendedorismo como um campo de pesquisa tem se intensificado, um número de novas perspectivas teóricas tem emergido para explicar as ações e as lógicas que impulsionam o comportamento empreendedor (Fisher, 2012). Duas abordagens utilizadas por empreendedores são definidas como causation, embasadas no planejamento e na análise, e effectuation, referente a estratégias emergentes e não preditivas (Chandler, Detienne, Mckelvie, \& Mumford, 2011).

Essas abordagens, desenvolvidas por Sarasvathy (2001), apresentam como principal diferença o conjunto de escolhas. Enquanto no processo causal as escolhas se referem aos melhores meios para se criar um determinado efeito, no processo effectual, as escolhas se referem a quais os efeitos possíveis a partir dos meios disponíveis. Sarasvathy (2001, p. 245) define essas abordagens como:

o processo causal toma um efeito particular como dado e foca na seleção entre meios para criação desse efeito. O processo effectual toma um conjunto de meios como dado e foca na seleção entre efeitos possíveis que podem ser criados a partir desses meios.

Enquanto os processos causais são excelentes para explorar situações conhecidas e são dependentes do efeito produzido, os processos effectuais são melhores na exploração de contingências e são dependentes do ator (Sarasvathy, 2001). Sendo assim, na abordagem causal, a oportunidade é fruto da avaliação analítica da informação. Na abordagem effectual, o produto final é imprevisível e a oportunidade é produzida de tal forma que, continuamente, transforma realidades existentes em possíveis mercados. Essa construção é determinada pelas contingências e feita pelos atores a partir de seus meios, experiências e parcerias (Read \& Sarasvathy, 2005). 
De acordo com Sarasvathy, Dew, Velamuri e Venkataraman (2010), a lógica effectual, ao iniciar sem nenhum objetivo dado, inverte os princípios chave e a lógica racional preditiva do paradigma causal. Nessa visão, as oportunidades não pré-existem, portanto, não podem ser reconhecidas ou descobertas. Elas são criadas a partir de um processo que envolve uma interação e uma negociação intensa entre stakeholders, para operacionalizar suas aspirações e valores em produtos, serviços e instituições concretas. Para ambas abordagens, a capacidade cognitiva do empreendedor é importante; no entanto, para a abordagem causal, a cognição influencia a determinação prévia de objetivos e modos de ação, enquanto, na effectual, influencia no "desenho de artefatos" em conjunto com outros atores (Augier \& Sarasvathy, 2004, p. 172). Fisher (2012) oferece uma visão geral e comparativa entre essas abordagens, representada na Tabela 2.

Tabela 2

\section{Abordagens Empreendedoras}

\begin{tabular}{|c|c|c|}
\hline & 1. Causation & 2. Effectuation \\
\hline \multirow[t]{5}{*}{$\begin{array}{l}\text { Quais fatores } \\
\text { explicam a } \\
\text { abordagem? }\end{array}$} & $\begin{array}{l}\text { - O Resultado é dado. } \\
\text { - Seleção entre meios para alcançar esse } \\
\text { resultado: }\end{array}$ & $\begin{array}{l}\text { - Conjunto de meios é dado. } \\
\text { - Seleção entre efeitos possíveis criados por } \\
\text { esses meios: }\end{array}$ \\
\hline & 1. Começo pelos fins. & 1. Começo pelos meios. \\
\hline & 2. Análise das expectativas de retorno. & 2. Princípio das perdas aceitáveis. \\
\hline & 3. Análise competitiva. & 3. Estabelecimento de relações estratégicas. \\
\hline & 4. Controle do Futuro. & 4. Aproveitamento de contingências. \\
\hline \multirow{2}{*}{$\begin{array}{l}\text { Como os fatores } \\
\text { identificados se } \\
\text { relacionam com } \\
\text { a busca por } \\
\text { resultados? }\end{array}$} & $\begin{array}{l}\text { Processos causation }>>\text { Identificam e } \\
\text { exploram oportunidades em mercados } \\
\text { existentes com baixo nível de incerteza. }\end{array}$ & $\begin{array}{l}\text { Processos de } \text { effectuation }>>\text { Identificam e } \\
\text { exploram oportunidades em novos mercados } \\
\text { com altos níveis de incerteza. }\end{array}$ \\
\hline & $\begin{array}{l}\text { - Participantes posteriores em uma indústria } \\
\text { >> Processos de causalidade. }\end{array}$ & $\begin{array}{l}\text { - Operadores de início bem sucedidos em uma } \\
\text { nova indústria >> processo de effectuation. } \\
\text { - Empresas efecttual >> Falha precoce e mais } \\
\text { barata. }\end{array}$ \\
\hline \multirow{2}{*}{$\begin{array}{l}\text { Por que essas } \\
\text { relações entre os } \\
\text { fatores e os } \\
\text { resultados } \\
\text { existem? }\end{array}$} & A teoria da decisão: & A teoria da decisão: \\
\hline & $\begin{array}{l}\text { Os decisores lidam com futuro mensurável } \\
\text { ou previsível, e farão a coleta de } \\
\text { informações e a análise sistemática dentro de } \\
\text { certos limites (Simon, 1959). }\end{array}$ & $\begin{array}{l}\text { Os decisores lidam com fenômenos } \\
\text { imprevisíveis e vão reunir informações através } \\
\text { de técnicas experimentais e interativas, } \\
\text { destinadas a descobrir o futuro da } \\
\text { aprendizagem. }\end{array}$ \\
\hline $\begin{array}{l}\text { Quem, Onde e } \\
\text { Quando as } \\
\text { afirmações e } \\
\text { limitações acerca } \\
\text { da teoria. }\end{array}$ & $\begin{array}{l}\text { - Ambiente estático, linear. } \\
\text { - Aspectos previsíveis de um futuro incerto } \\
\text { são discerníveis e mensuráveis. } \\
\text { - Oportunidades empresariais são objetivas e } \\
\text { identificáveis a priori. }\end{array}$ & $\begin{array}{l}\text { - Dinâmico não linear e ambientes ecológicos. } \\
\text { - O futuro é desconhecido e não mensurável. } \\
\text { - Oportunidades empreendedoras são } \\
\text { subjetivas, socialmente construídas e criadas. }\end{array}$ \\
\hline
\end{tabular}

Nota. Fisher, G. (2012). Effectuation, causation, and bricolage: a behavioral comparison of emerging theories in entrepreneurship research (p. 1022). Entrepreneurship Theory and Practice, 36(5), 1019-1051. doi: 10.1111/j.15406520.2012.00537.x

$\mathrm{Na}$ abordagem causal, os fatores importantes para compreensão consistem no estabelecimento prévio dos objetivos, na análise das restrições ambientais e na análise dos meios necessários para o cumprimento dos objetivos, de forma a maximizar o retorno sobre o investimento. Para essa abordagem, raramente são criados novos mercados, ocorrendo a ação empreendedora em mercados pré-existentes, caracterizando-se como novos entrantes em indústrias já estabelecidas. O ambiente é tido como estável e linear, sendo mensurável ou relativamente previsível, o que favorece uma busca 
sistemática por informações, bem como a definição prévia dos objetivos e o estabelecimento de planos (Fisher, 2012).

De acordo com Chandler et al. (2011), no processo causal, o indivíduo toma decisões racionais baseado nas informações relevantes disponíveis e em uma expectativa de retorno oferecida por cada opção identificada e analisada. Segundo Casson e Wadeson (2007), cabe ao empreendedor, após uma análise do ambiente, escolher entre possíveis projetos disponíveis, sendo o processo empreendedor, nesse conceito, constituído por três principais funções: descoberta de uma oportunidade, procura de recursos para o projeto e a realização dos benefícios por meio da implantação do projeto.

Um elemento importante na abordagem causal é a elaboração do plano de negócios, um documento que descreve os estados atual e futuro da organização, uma atividade racional que procura auxiliar empreendedores a obter lucros maiores por meio da projeção de ganhos de eficiência ou do aumento de venda (Honig \& Karlsson, 2004). No entanto, Chandler et al. (2011) ponderam sobre a real efetividade do plano de negócios.

Por outro lado, na abordagem effectual, a premissa considera que, em condições de incerteza, empreendedores adotarão uma lógica de decisão diferente do modelo tradicional e racional, definido como causal. Conforme essa abordagem, são os meios de que o empreendedor dispõe que podem ser explorados, em consonância com o princípio das perdas aceitáveis, ou seja, quanto realmente o empreendedor está disposto a perder ou a se arriscar. Além disso, o estabelecimento de relacionamentos estratégicos é importante para aumentar os meios disponíveis e favorecer a exploração de contingências, transformando-as em oportunidades lucrativas. A lógica effectual se relaciona com a exploração de oportunidades em novos mercados com alto grau de incerteza, favorecendo um processo experimental e um aprendizado interativo que permitem ao empreendedor descobrir informações sobre o futuro, considerando o ambiente como dinâmico, não linear, sendo o futuro desconhecido e não mensurável (Fisher, 2012).

Frese (2009) ressalta que o empreendedor, de acordo com a abordagem effectuation, busca encontrar a melhor combinação dos meios que ele tem disponível, como habilidades, recursos financeiros e materiais, acesso ao mercado, entre outros. Uma vez identificado espaço no mercado, resultante dessa combinação, novos passos são dados para alcançar um sucesso ainda maior. Portanto, no processo effectual, o empreendedor explora ativamente o ambiente para encontrar mais e melhores formas de acesso aos mercados para novos produtos e serviços, ao invés de ter seu comportamento moldado por este mesmo mercado.

Sarasvathy e Dew (2005) salientam que empreendedores effectuais partem de uma autorreflexão sobre quem eles são, sobre quais conhecimentos possuem e sobre quem eles conhecem. Com isso, a ação é resultante dos meios disponíveis, do que o empreendedor julga que pode fazer, bem como da interação com pessoas conhecidas. A interação é resultante de negociações que visam estabelecer acordos que permitam acessos a novos meios e combinações. Nesse cenário, no início do processo, o produto final é imprevisível, pois depende de quais atores se comprometerão. Assim, as oportunidades serão criadas a partir de um processo que se transforma continuamente, sendo centrado na ação dos atores sobre o meio.

Chandler et al. (2011) desenvolveram e validaram uma escala para avaliar a utilização das abordagens causation e effectuation por empreendedores. A abordagem causation apresentou melhor adequação como um constructo unidimensional, enquanto que a effectuation melhor se apresentou como multidimensional, formada pelas dimensões experimentação, perdas aceitáveis, flexibilidade e pré-acordos. A escala desenvolvida é composta por 20 itens, como mostra a Tabela 3. 
Tabela 3

Escala das Abordagens Causation e Effectuation

\begin{tabular}{|c|c|}
\hline Dimensão & Itens \\
\hline \multirow[t]{7}{*}{ Causation } & $\begin{array}{l}\text { Analisei as oportunidades a longo prazo e selecionei aquelas sobre que pensei oferecer o } \\
\text { melhor retorno. }\end{array}$ \\
\hline & Desenvolvi uma estratégia para melhor tirar vantagem dos recursos e capacidades disponíveis. \\
\hline & Desenvolvi e planejei um plano de negócios. \\
\hline & $\begin{array}{l}\text { Organizei e implementei processos de controle para me certificar sobre o cumprimento dos } \\
\text { objetivos pré-estabelecidos. }\end{array}$ \\
\hline & Pesquisei e selecionei os mercados alvo e fiz uma análise competitiva significativa. \\
\hline & Tive uma visão clara e consistente sobre aonde eu gostaria de chegar. \\
\hline & Desenvolvi um plano de produção e de ações de marketing. \\
\hline \multirow[t]{4}{*}{ Experimentação } & Experimentei produtos diferentes e modelos de negócio diferentes. \\
\hline & $\begin{array}{l}\text { O produto/serviço oferecido agora é essencialmente o mesmo daquele originalmente } \\
\text { conceituado. }\end{array}$ \\
\hline & O produto/serviço oferecido agora é substancialmente diferente daquele imaginado primeiro. \\
\hline & Tentei uma série de métodos diferentes até encontrar um modelo de negócio que funcionasse. \\
\hline \multirow{3}{*}{$\begin{array}{l}\text { Perdas } \\
\text { Aceitáveis }\end{array}$} & Fui cuidadoso para não comprometer recursos além do que eu dispunha a perder \\
\hline & $\begin{array}{l}\text { Fui cuidadoso para não arriscar mais dinheiro além do que eu estava propenso a perder com a } \\
\text { ideia inicial. }\end{array}$ \\
\hline & $\begin{array}{l}\text { Fui cuidado para não arriscar tanto dinheiro a ponto de colocar a empresa em problemas } \\
\text { financeiros caso as coisas não dessem certo. }\end{array}$ \\
\hline \multirow[t]{4}{*}{ Flexibilidade } & $\begin{array}{l}\text { Permiti ao negócio desenvolver oportunidades emergentes (novas) além do que estava } \\
\text { planejado. }\end{array}$ \\
\hline & Adaptei o que iríamos fazer aos recursos que eu tinha disponíveis. \\
\hline & Fui flexível e tirei vantagens das oportunidades enquanto elas surgiam. \\
\hline & Evitei ações que restringiam a flexibilidade e a adaptabilidade do negócio. \\
\hline \multirow[t]{2}{*}{ Pré-acordos } & $\begin{array}{l}\text { Usei um número substancial de acordos com clientes, fornecedores e outras organizações e } \\
\text { pessoas para reduzir o tamanho da incerteza. }\end{array}$ \\
\hline & Usei pré-acordos para clientes e fornecedores sempre que foi possível. \\
\hline
\end{tabular}

Nota. Chandler, G. N., Detienne, D. R., Mckelvie, A., \& Mumford, T. V. (2011). Causation and effectuation processes: a validation study (p. 382). Journal of Business Venturing, 26(1), 375-390. doi: 10.1016/j.jbusvent.2009.10.006

Cabe ressaltar que não é possível estabelecer uma abordagem como melhor. A adoção de cada processo e os resultados obtidos por meio deles dependerá de cada situação e de suas particularidades (Harms \& Schiele, 2012). Além disso, de acordo com Fisher (2012), as abordagens não são excludentes, podendo ser combinadas para um maior sucesso na constituição e na condução de novos empreendimentos. 


\section{Procedimentos Metodológicos}

\section{Amostra e instrumento de coleta de dados}

O presente estudo foi realizado junto a 123 empresários concentrados em duas cidades do estado do Paraná, participantes de associações comerciais. As cidades pertencem à região norte do estado e distam entre si $35 \mathrm{~km}$. Ambas têm como principais atividades econômicas a agricultura e o comércio. Os empreendimentos participantes da pesquisa são, predominantemente, comércios varejistas e prestadores de serviços de micro e pequeno porte. A técnica de amostra utilizada foi a não probabilística por conveniência e por bola de neve (Malhotra, 2001). O contato inicial com os empreendedores se deu por meio da participação em reuniões nas próprias associações, explicando os objetivos da pesquisa. Posteriormente, as associações forneceram endereços de demais associados. Primeiramente, a coleta de dados foi realizada in loco nas reuniões das associações, totalizando 46 respondentes. Na sequência, a coleta de dados prosseguiu por meio de um link específico na internet, acompanhado de explicação dos objetivos da pesquisa, resultando em 77 respondentes. O instrumento de coleta de dados foi o questionário estruturado, abrangendo as escalas para mensuração do alerta e das abordagens empreendedoras, conforme explicado no próximo item.

Para todas as variáveis utilizadas no presente trabalho, foram realizados testes $T$ para avaliar se as médias das respostas eram significativamente diferentes, o que poderia comprometer os resultados do estudo. Foram avaliadas as diferenças de médias entre os grupos quanto ao acesso (in loco ou internet) e quanto às cidades. Os valores dos testes evidenciaram que não houve diferenças significativas nas respostas entre os respondentes in loco e os respondentes pela internet $(p>0,16)$. Da mesma forma, também não foram encontradas diferenças significativas entre as médias das respostas dos empreendedores das duas cidades $(p>0,20)$.

\section{Variáveis}

Para mensurar o grau de alerta empreendedor, foi utilizada a escala desenvolvida e validada após três estudos por Tang et al. (2012). A escala é constituída por 13 itens divididos em três dimensões: varredura e procura (seis itens), associação e conexão (três) e avaliação e julgamento (quatro). Quanto ao processo empreendedor, utilizou-se a escala desenvolvida pelo estudo de Chandler et al. (2011), a qual possui 20 itens, divididos em 5 dimensões. A primeira dimensão refere-se à abordagem causation (sete itens), enquanto as demais à abordagem effectuation: experimentação (quatro), perdas acessíveis (três), flexibilidade (quatro) e pré-acordos (dois). Para ambas as escalas, utilizou-se uma escala do tipo Likert de cinco pontos ancorada por 1 - discordo totalmente e 5 concordo totalmente. Inicialmente, procedeu-se a tradução e a aplicação das escalas em um grupo de estudantes de mestrado em Administração, a fim de validar a tradução. Posteriormente, o instrumento foi enviado aos participantes da pesquisa.

\section{Variáveis de controle}

Os respondentes foram convidados ainda a responder algumas variáveis de controle que integraram o modelo de análise. Essa inclusão almejou observar o quanto as variações ocorridas nas variáveis que mensuram as abordagens empreendedoras se dão por outras variáveis que não a desejada, representada nesse estudo pelo alerta empreendedor. As variáveis de controle foram: experiência como empreendedor, expressa em anos; tamanho dos empreendimentos, expresso pela quantidade de funcionários empregados; experiência em novos empreendimentos, retratado pela quantidade de empreendimentos desenvolvidos anteriormente, amplitude como empreendedor, apresentada pela quantidade de empreendimentos em desenvolvimento. Outras variáveis foram ainda coletadas como gênero, idade, renda familiar mensal e grau de escolaridade. 


\section{Método de análise}

Primeiramente, os itens das escalas foram submetidos a testes para avaliar a normalidade multivariada. Dado o tamanho da amostra, os testes usuais de ajustamentos à distribuição normal, como o Kolmogorov-Smirnov e Shapiro-Wilk, tornam-se sensíveis a pequenos desvios à normalidade, sendo desaconselháveis para aplicações como esse estudo (Marôco, 2010). Foram então avaliadas as medidas de assimetria e curtose e os maiores valores de coeficiente encontrados foram 1,69 e 2,42, respectivamente. Ambas as medidas se encontram dentro dos parâmetros descritos por Marôco (2010), valores inferiores a 2 para assimetria e inferiores a 3 para curtose, pressupondo a normalidade dos dados.

Em seguida, procedeu-se a validação das escalas e de suas dimensões, garantido a sua utilização.. Para validação, utilizou-se a técnica estatística análise fatorial que busca, através da avaliação de um conjunto de variáveis, identificar dimensões de variabilidade comuns existentes em um conjunto de fenômenos. Esta técnica objetiva simplificar ou reduzir um grande número de variáveis por meio da determinação das dimensões latentes comuns (fatores) (Bezerra, 2012; Fávero, Belfiore, Silva, \& Chan, 2009).

Os fatores extraídos foram submetidos ao teste de confiabilidade Alfa de Cronbach que mede a sua consistência interna, ou seja, indica se os itens individuais da escala realmente medem determinado constructo, estando altamente intercorrelacionados (Bezerra, 2012; Fávero et al., 2009). Após validadas as dimensões, foram testadas as relações entre alerta empreendedor e as abordagens por meio dos testes de dependência correlação de Pearson e regressão linear. O teste de correlação bivariado envolve apenas duas variáveis e analisa o grau de predição entre elas, ou seja, o quanto uma varia em função da outra. A análise de regressão é usada para analisar a contribuição relativa ou o grau de predição de uma ou mais variáveis independentes no comportamento de uma variável dependente (Hair, Black, Babin, Anderson, \& Tatham, 2009).

Além disso, foram também realizados testes para avaliar a existência de multicolinearidade entre as variáveis independentes do modelo de regressão, a fim de não comprometer os resultados das análises (Marôco, 2010). Os testes foram realizados com auxílio do software estatístico SPSS versão 20.

\section{Apresentação e Análise dos Resultados}

A maioria dos respondentes foi representada por empresários do sexo masculino $(75,6 \%)$. Aproximadamente $70 \%$ dos respondentes afirmaram ter concluído ensino superior. A idade média dos pesquisados é de 34,9 anos, com uma renda familiar média mensal de $\mathrm{R} \$ 18.797,30$. Quanto ao tempo de atuação, os respondentes apresentaram um tempo médio de atuação de 7,3 anos, enquanto seus empreendimentos são, predominantemente, considerados micro e pequenas empresas, conforme classificação proposta pelo Serviço Brasileiro de Apoio às Micro e Pequenas Empresas (SEBRAE, 2011). A média de pessoas ocupadas foi de 19 e o desvio padrão de 45. Os principais dados da amostra estão representados na Tabela 4. 
Tabela 4

\section{Descrição da Amostra}

\begin{tabular}{lc}
\hline Características & Empreendedores (n=123) \\
\hline Gênero & \\
$\quad$ Masculino & $75,60 \%$ \\
$\quad$ Feminino & $24,40 \%$ \\
Educação & \\
$\quad$ Ensino fundamental & $2,44 \%$ \\
$\quad$ Ensino médio & $27,64 \%$ \\
$\quad$ Ensino superior & $39,02 \%$ \\
$\quad$ Pós-graduação (Especialização) & $27,64 \%$ \\
$\quad$ Mestrado & $3,25 \%$ \\
Idade Média (anos) & $34,9(12,3)^{\mathrm{a}}$ \\
Renda familiar mensal (R\$) & $18.797,30(57.068,58)^{\mathrm{a}}$ \\
Experiência (anos) & $7,3(7,2)^{\mathrm{a}}$ \\
Tamanho dos empreendimentos (funcionários) & $19(45)^{\mathrm{a}}$ \\
\hline
\end{tabular}

Nota. ${ }^{\text {a }}$ Média (Desvio padrão).

Para atingir os objetivos da pesquisa, ambas as escalas de alerta empreendedor e das abordagens empreendedoras foram submetidas à técnica de interdependência análise fatorial exploratória, visando analisar a estrutura de inter-relações dos itens e o agrupamento dos mesmos em conjuntos (fatores) (Hair et al., 2009). Esses agrupamentos de itens formam as variáveis latentes, as quais não podem ser mensuradas de forma direta. Na realização do teste, optou-se pela utilização do método de rotação ortogonal das variáveis VARIMAX, que permite uma separação mais clara dos fatores, os quais não tiveram sua quantidade definida previamente (Hair et al., 2009).

Conforme já mencionado, a escala para mensuração do alerta empreendedor utilizada foi desenvolvida por Tang et al. (2012). Ela se constitui a partir de 13 itens divididos em três dimensões que avaliam o grau em que o empresário está atento e procura por informações; a sua capacidade de associar e conectar as informações coletadas para exploração de novas oportunidades (conectar os pontos); e a sua capacidade para avaliar e julgar as oportunidades identificadas. Os resultados da analise fatorial para essa escala estão evidenciados na Tabela 5. A solução encontrada apresentou um agrupamento claro dos itens em três dimensões, sendo esse agrupamento conforme o esperado. Poucos itens apresentaram cargas fatoriais em outra dimensão além da esperada e, quando ocorrido, apresentaram carga fatorial inferior. Para uma amostra de aproximadamente 120 elementos, considerase uma carga fatorial significativa valores superiores 0,50 (Hair et al., 2009). Os itens da escala de alerta empreendedoras atenderam essa condição, portanto são considerados aceitáveis. 
Tabela 5

\section{Dimensões de Alerta Empreendedor e Alfa de Cronbach}

\begin{tabular}{lc}
\hline Variáveis latentes e itens da escala & Carga fatorial \\
\hline Varredura e Procura & $\underline{\alpha=0,858}$ \\
Eu interajo frequentemente com os outros para adquirir novas informações. & 0,804 \\
Eu sempre estou atento a novas ideias de negócios quando vejo alguma informação. & 0,680 \\
Eu leio jornais, revistas ou publicações regularmente para adquirir novas informações. & 0,572 \\
Eu navego na internet todos os dias na busca por informações. & 0,735 \\
Eu sou um ávido (insaciável) buscador de informações. & 0,810 \\
Eu estou sempre procurando ativamente novas informações. & 0,777 \\
Associação e Conexão & $\underline{\alpha=0,865}$ \\
Eu vejo associações entre informações aparentemente não relacionadas. & 0,778 \\
$\begin{array}{l}\text { Eu sou bom em conectar pontos (descobrir oportunidades relacionando fatos aparentemente não } \\
\text { relacionados). }\end{array}$ & 0,855 \\
$\begin{array}{l}\text { Eu costumo ver conexões entre informações de vários domínios de conhecimento aparentemente } \\
\text { desconexos. }\end{array}$ & 0,854 \\
Avaliação e Julgamento & $\underline{\alpha=0,802}$ \\
$\begin{array}{l}\text { Eu tenho um instinto para encontrar oportunidades com potencial. } \\
\text { Eu consigo distinguir entre oportunidades lucrativas e oportunidades não tão lucrativas. }\end{array}$ & 0,461 \\
$\begin{array}{l}\text { Eu tenho um talento para separar oportunidades de alto valor das oportunidades de baixo valor. } \\
\text { Ao me deparar com várias oportunidades, eu sou capaz de selecionar as boas. }\end{array}$ & 0,872 \\
\hline
\end{tabular}

Para testar o grau de confiabilidade e de consistência interna de cada dimensão, utilizou-se o coeficiente de Alfa de Cronbach $(\alpha)$. Em análises exploratórias como esta, são tidos como significantes valores superiores a 0,60 (Hair et al., 2009). Os resultados encontrados nessa escala foram todos superiores a 0,80 , sugerindo uma validade convergente, alta correlação entre os itens de cada dimensão e significância para mensurarem essa variável latente.

Como mostra a Tabela 6, o mesmo procedimento foi adotado para a escala de mensuração das abordagens empreendedoras causation e effectuation, composta por 20 itens. Esperava-se que os itens se agrupassem em cinco dimensões, as quais avaliam o processo empreendedor a partir da abordagem causal; do grau de experimentação; das perdas aceitáveis; do grau de flexibilidade; e da utilização de pré-acordos. A primeira dimensão se refere à abordagem causation, enquanto as demais tratam da abordagem effectuation. 
Tabela 6

\section{Dimensões das Abordagens Empreendedoras e Alfa de Cronbach}

\begin{tabular}{l} 
Variáveis latentes e itens da escala \\
\hline Causation \\
Analisei as oportunidades a longo prazo e selecionei aquelas que pensei oferecerem o melhor \\
retorno.
\end{tabular}
retorno.

Carga fatorial

Desenvolvi uma estratégia para melhor tirar vantagem dos recursos e capacidades disponíveis.

$\underline{\alpha=0,820}$

Desenvolvi e planejei um plano de negócios.

0,782

0,713

Organizei e implementei processos de controle para me certificar sobre o cumprimento dos

objetivos pré-estabelecidos.

0,810

Pesquisei e selecionei os mercados-alvo e fiz uma análise competitiva significativa.

Tive uma visão clara e consistente sobre aonde eu gostaria de chegar.

Desenvolvi um plano de produção e de ações de marketing.

Experimentação

Experimentei produtos diferentes e modelos de negócio diferentes.

O produto/serviço oferecido agora é essencialmente o mesmo daquele originalmente conceituado ${ }^{\mathrm{r}}$. (R)

O produto/serviço oferecido agora é substancialmente diferente daquele imaginado primeiro.

Tentei uma série de métodos diferentes até encontrar um modelo de negócio que funcionasse.

Perdas Aceitáveis

Fui cuidadoso para não comprometer recursos além do que eu dispunha a perder.

$\underline{\alpha=0,888}$

0,814

Fui cuidadoso para não arriscar mais dinheiro além do que eu estava propenso a perder com a ideia inicial.

Fui cuidado para não arriscar tanto dinheiro a ponto de colocar a empresa em problemas financeiros caso as coisas não dessem certo.

Flexibilidade

Permiti ao negócio desenvolver oportunidades emergentes (novas) além do que estava planejado.

Adaptei o que iríamos fazer aos recursos que eu tinha disponível.

Fui flexível e tirei vantagens das oportunidades enquanto elas surgiam.

Evitei ações que restringiam a flexibilidade e a adaptabilidade do negócio.

Pré-acordos

Usei um número substancial de acordos com clientes, fornecedores e outras organizações e pessoas para reduzir o tamanho da incerteza.

Usei pré-acordos para clientes e fornecedores sempre que foi possível.

Nota. ${ }^{\mathrm{r}}$ Item revertido. ${ }^{\mathrm{a}}$ Itens removidos para adequação da análise fatorial, baixo índice de carga (lambda).

A primeira solução gerada apresentou duas dimensões a mais, não esperadas, em que alguns itens da escala apresentaram cargas fatoriais significativas. Os itens com maiores cargas nessas dimensões pertenciam às dimensões de experimentação - experimentei produtos diferentes e modelos de negócio diferentes e tentei uma série de métodos diferentes até encontrar um modelo de negócio que funcione - e de flexibilidade - permiti ao negócio desenvolver oportunidades emergentes (novas) além do que estava planejado e evitei ações que restringiam a flexibilidade e a adaptabilidade do negócio. Esses itens foram removidos para realizações de novos testes que deram origem a uma 
solução satisfatória com as cinco dimensões e com o agrupamento de itens da forma esperada. As cargas fatoriais, apresentadas na Tabela 6 se demonstraram satisfatórias $(\lambda>0,50)$, bem como os índices de confiabilidade das dimensões $(\alpha>0,60)$.

Validadas as dimensões das escalas do alerta empreendedor e das abordagens empreendedoras, foram calculadas as variáveis latentes por meio da média simples dos seus itens, as quais foram submetidas aos testes de associação. O primeiro teste realizado foi o cálculo de correlação bivariada. Além das variáveis latentes alerta empreendedor, causation e effectuation, foram correlacionados as variáveis de controle: amplitude (quantidade de negócios atuais), experiência (tempo em anos como empreendedor), tamanho dos empreendimentos (pessoas ocupadas) e experiência na abertura de novos empreendimentos (quantos negócios já iniciou). Os resultados estão representados na Tabela 7. Além dos coeficientes de correlação, são apresentados também os valores de média e de desvio padrão para cada variável.

Tabela 7

Média, Desvio Padrão e Coeficiente de Correlação entre as Variáveis

\begin{tabular}{|c|c|c|c|c|c|c|c|c|c|c|}
\hline Variável & Média & DP & 1 & 2 & 3 & 4 & 5 & 6 & 7 & 8 \\
\hline 1 Amplitude & 1,44 & 1,08 & 1 & & & & & & & \\
\hline 2 Experiência & 7,34 & 7,15 & 0,15 & 1 & & & & & & \\
\hline 3 Tamanho & 19,19 & 44,82 & $0,47 * *$ & $0,21 *$ & 1 & & & & & \\
\hline 4 Novos Empreend. & 0,63 & 2,60 & 0,02 & $-0,03$ & $-0,05$ & 1 & & & & \\
\hline 5 Idade & 34,87 & 12,32 & 0,03 & $0,62 * *$ & $-0,01$ & 0,02 & 1 & & & \\
\hline 6 Alerta Empreend. & 3,65 & 0,68 & $-0,06$ & $-0,31 * *$ & 0,09 & $-0,02$ & $-0,36 * *$ & 1 & & \\
\hline 7 Causation & 3,49 & 0,83 & 0,06 & $-0,26 * *$ & 0,06 & $-0,08$ & $-0,34 * *$ & $0,35^{* *}$ & 1 & \\
\hline 8 Effectuation & 3,47 & 0,56 & 0,04 & 0,03 & 0,13 & $-0,05$ & $-0,16$ & $0,25 * *$ & $0,29 * *$ & 1 \\
\hline
\end{tabular}

Nota. $* * \mathrm{p}<0,01 ; * \mathrm{p}<0,05$ (bi-caudal).

Como é possível observar na Tabela 7 , os resultados apontaram uma correlação negativa e significativa entre alerta empreendedor e experiência $(r=-0,31)$ e entre alerta e idade $(r=-0,36)$, indicando que, quanto maior for a experiência do indivíduo enquanto empreendedor ou quanto maior a sua idade, menor será o seu estado de alerta a novas oportunidades empreendedoras. Dew, Read, Sarasvathy e Wiltbank (2009) demonstraram que empreendedores com grande experiência tendem a dispensar informações prévias em detrimento da sua intuição e experiência pessoal no processo de tomada de decisão. Quanto à abordagem causation, os resultados indicam uma correlação negativa e significativa também com experiência $(r=-0,26)$ e idade $(r=-0,34)$. Da mesma forma, quanto maior a experiência ou a idade do empreendedor, menor será o seu grau de adoção da abordagem causation. Além disso, essa abordagem também se correlacionou significativamente, dessa vez de forma positiva, com alerta empreendedor $(r=0,35)$. Quanto maior o estado de alerta do empreendedor, maior o grau de adoção de uma abordagem causal. Essa correlação, inclusive, obteve o maior coeficiente de correlação para essa abordagem.

No caso da variável effectuation, foram evidenciadas correlações significativas e positivas com alerta empreendedor $(r=0,25)$ e também com a própria abordagem causal $(r=0,29)$. Os resultados demonstram que, quanto maior for o grau de alerta, maior será também o grau de adoção da abordagem effectuation, apesar do coeficiente de correlação ser inferior ao da relação com a abordagem causal. Assim, o alerta empreendedor foi mais relacionado com a abordagem causal do que com a abordagem effectuation. Os resultados demonstram também que as duas abordagens podem ser adotadas simultaneamente, inclusive com uma relação positiva, ou seja, quanto maior for a adoção de uma abordagem causal, também maior tende a ser a adoção da abordagem effectuation. 
Para melhor análise das relações envolvendo as abordagens empreendedoras, as variáveis foram submetidas à análise de regressão linear representada na Tabela 8. Foram elaborados 4 modelos de regressão lineares múltiplas que avaliam o poder de explicação de uma única variável dependente (causation ou effectuation) por múltiplas variáveis independentes, nesse caso, as variáveis de controle. Em dois dos modelos, foram acrescidas ao rol de variáveis independentes também as variáveis causation e effectuation. Assim, no modelo em que a variável causation era a dependente, a variável effectuation foi incluída como independente. No outro modelo, em que a variável effectuation era a dependente, a variável causation foi incorporada como independente. Para a realização dos testes, além dos coeficientes de regressão, foram analisadas também as medidas de multicolinearidade das variáveis independentes (VIF). A existência de multicolinearidade representa forte associação entre as variáveis independentes, podendo inflacionar a estimação das variâncias. No entanto, para essa amostra, não foram identificados valores superiores a 1,84, não comprometendo as análises (Marôco, 2010).

Tabela 8

Análise de Regressão das Abordagens Empreendedoras

\begin{tabular}{|c|c|c|c|c|c|c|c|c|}
\hline \multirow[b]{2}{*}{ Variável } & \multicolumn{4}{|c|}{ Causation } & \multicolumn{4}{|c|}{ Effectuation } \\
\hline & Beta $\left(\beta_{1}\right)$ & $t$ Valor & Beta $\left(\beta_{2}\right)$ & $t$ Valor & Beta $\left(\beta_{3}\right)$ & $t$ Valor & $\operatorname{Beta}\left(\beta_{4}\right)$ & $t$ Valor \\
\hline Amplitude & 0,09 & 0,98 & 0,09 & 1,00 & 0,00 & 0,00 & $-0,02$ & $-0,22$ \\
\hline Experiência & $-0,08$ & $-0,68$ & $-0,12$ & $-1,10$ & 0,22 & $1,92^{*}$ & 0,24 & $2,11 *$ \\
\hline Tamanho & 0,00 & 0,02 & $-0,01$ & $-0,10$ & 0,06 & 0,57 & 0,06 & 0,57 \\
\hline Novos Empreend. & $-0,07$ & $-0,87$ & $-0,07$ & $-0,82$ & $-0,03$ & $-0,31$ & $-0,01$ & $-0,12$ \\
\hline Idade & $-0,20$ & $-1,80$ & $-0,15$ & $-1,41$ & $-0,21$ & $-1,84$ & $-0,17$ & $-1,46$ \\
\hline Alerta Empreend. & 0,26 & $2,78 * *$ & 0,21 & $2,23 *$ & 0,24 & $2,51^{*}$ & 0,18 & 1,89 \\
\hline Causation & & & & & & & 0,22 & $2,36^{*}$ \\
\hline Effectuation & & & 0,21 & $2,36^{*}$ & & & & \\
\hline $\mathrm{R}^{2}$ & \multicolumn{2}{|c|}{0,19} & \multicolumn{2}{|c|}{0,22} & \multicolumn{2}{|c|}{0,11} & \multicolumn{2}{|c|}{0,15} \\
\hline
\end{tabular}

Nota. Beta $(\beta)=$ Coeficientes padronizados de regressão. ${ }^{*} \mathrm{p}<0,01 ;{ }^{*} \mathrm{p}<0,05$.

Os modelos de regressão testados para a abordagem causation apresentaram valores de poder explicativo, coeficiente de ajuste $\left(\mathrm{R}^{2}\right)$, superiores aos modelos da abordagem effectuation, sendo, portanto, mais satisfatórios. Os resultados indicam que as variáveis significativas para explicar a abordagem causation foram alerta empreendedor $\left(\beta_{1}=0,26\right.$ e $\left.\beta_{2}=0,21\right)$ e abordagem effectuation $\left(\beta_{2}=\right.$ $0,21)$. No segundo modelo, a abordagem effectuation apresentou, inclusive, efeito superior, pois, apesar de apresentaram o mesmo coeficiente de regressão, apresentou maior grau de significância. Assim, os resultados indicam uma relação linear positiva entre causation e as variáveis alerta empreendedor e effectuation, ou seja, quanto maior o alerta e quanto maior a adoção de práticas effectuais, maior será também a adoção de práticas causais, evidenciando a importância do alerta para o Empreendedorismo.

Para a abordagem effectuation, a variável de controle experiência foi significativa para os dois modelos $\left(\beta_{3}=0,22\right.$ e $\left.\beta_{4}=0,24\right)$, enquanto alerta empreendedor foi significativo para apenas um $\left(\beta_{3}=\right.$ $0,24)$. No modelo em que foi adicionada a variável causation, o alerta empreendedor não apresentou mais poder significativo de explicação, sendo suprimido por essa variável $\left(\beta_{4}=0,22\right)$ em função do poder preditivo compartilhado por ambas. Portanto, os resultados indicam uma relação linear positiva entre a abordagem effectuation e a experiência empreendedora, e a abordagem causal. Quanto maior for a experiência do indivíduo à frente dos seus empreendimentos e quanto maior a adoção de práticas 
empreendedoras causais, maior será também a possibilidade de adoção da abordagem effectuation. As demais relações testadas nos quatro modelos e não citadas não se mostraram significativas $(p>0,05)$.

Em uma análise geral, pode-se destacar que há uma relação entre o grau de alerta empreendedor e as abordagens empreendedoras, objetivo principal desta pesquisa, porém é mais forte para a abordagem causal. Outro resultado importante refere-se à relação existente entre as duas abordagens, que também se mostrou positiva, indicando não serem abordagens excludentes ou dicotômicas, como evidenciado anteriormente por Fisher (2012).

Para melhor análise da relação entre o alerta empreendedor e a abordagem causal foi testado também um modelo de regressão não linear simples. Foi adotado um modelo quadrático, polinomial de segundo grau, que permite realizar avaliações mais complexas do comportamento da variável dependente (causation) a partir da variável independente (alerta empreendedor), como um possível formato curvilíneo de $\mathbf{U}$ ou $\mathbf{U}$ invertido (Hair et al., 2009).

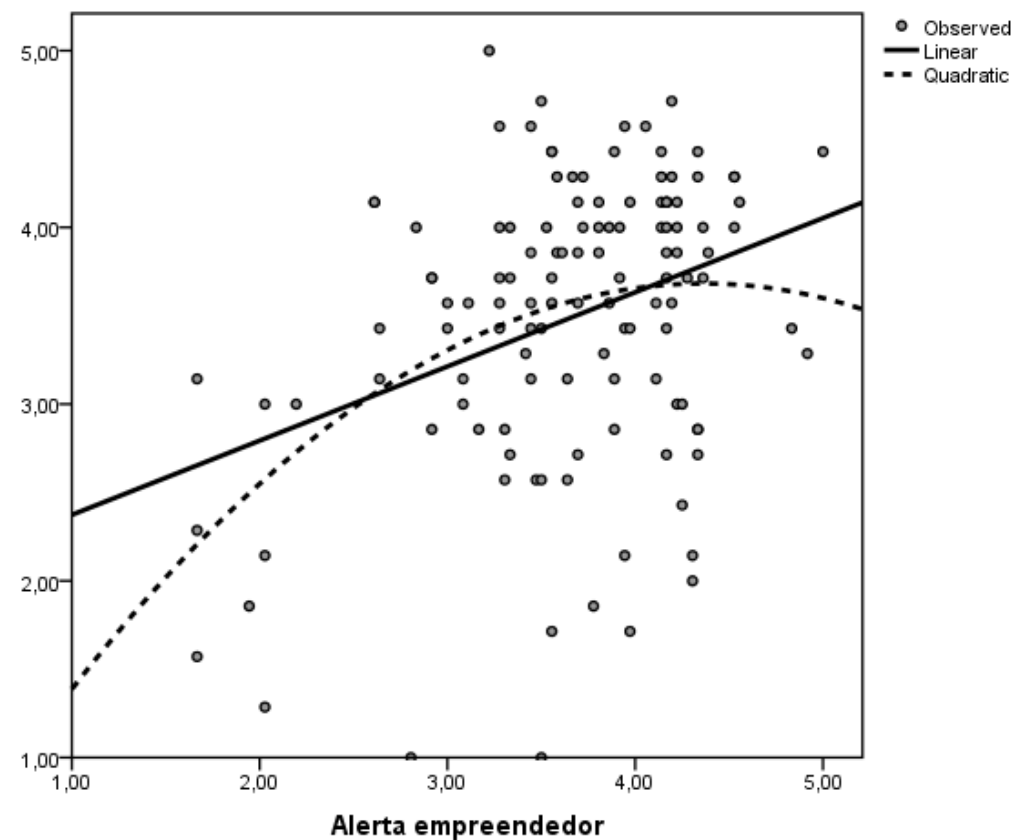

Figura 2. Efeito Curvilinear em ' $U$ ' Invertido do Alerta Empreendedor sobre a Abordagem Causation.

Fonte: Autores da pesquisa.

O modelo não linear elaborado explica $15 \%$ da variação da abordagem causal, enquanto o modelo linear simples explica 12\%. Ambos são significativos e rejeitam a hipótese nula de não haver relação entre a variável dependente (alerta) e a independente (abordagem causal). Como observado na Figura 2, o efeito encontrado da variável alerta empreendedor sobre a abordagem causation foi curvilinear, no formato de um $\mathbf{U}$ invertido. Esse efeito aponta para um nível ótimo (máximo) de alerta empreendedor, em que quanto maior o alerta, maior a adoção de práticas causais. Entretanto, em determinado ponto (situado no gráfico entre os níveis 3 e 4), a relação se inverte, ou seja, quanto mais se eleva o grau de alerta, o nível de adoção da abordagem causal passa a decrescer.

\section{Considerações Finais}

O objetivo principal desse trabalho foi avaliar a relação existente entre o grau de alerta empreendedor com os constructos causation e effectuation. Para tanto, um objetivo específico consistiu na validação dessas escalas desenvolvidas, respectivamente, por Tang et al. (2012) e 
Chandler et al. (2011). A escala de alerta empreendedor apresentou uma solução clara, com um agrupamento dos itens conforme esperados nas dimensões de alerta: varredura e procura; associação e conexão; e avaliação e julgamento. Na escala referente às abordagens causal e effectual, alguns itens apresentaram cargas fatoriais diferentes do esperado. Das cinco dimensões testadas, - uma para causation e quatro para effectuation (experimentação, perdas acessíveis, flexibilidade e pré-acordos), duas apresentaram resultados insatisfatórios, sendo necessário a exclusão dos itens para uma solução adequada: experimentação e flexibilidade. É importante ressaltar que a utilização de medidas objetivas para as abordagens empreendedoras não despreza a intersubjetividade da abordagem effectuation já reconhecida pela teoria. As escalas são destinadas a avaliar apenas a ação dos atores sobre o meio, ou seja, o modo como os empreendedores operam.

Adequadas as escalas, foram então analisadas as relações existentes entre elas, bem como com as variáveis de controle adicionadas aos modelos. $\mathrm{O}$ primeiro achado refere-se às relações negativas entre idade e experiência com o alerta empreendedor. Esta pesquisa mostrou que, com o passar dos anos, seja de idade ou da própria experiência à frente de empreendimentos, as ações de pesquisa e procura deliberada por informações, a capacidade de conectar os pontos (Baron, 2006) e de avaliar e julgar novas oportunidades tende a reduzir. Nesse sentido, pessoas mais experientes tendem a demonstrar um estado de alerta menor porque tendem a confiar mais nos meios que dispõem.

Quanto à experiência empreendedora, a redução no nível de alerta pode ser justificada por uma possível estabilidade do negócio e segurança à frente do mesmo, adquirida ao longo do tempo. Essa mesma variável de controle também se correlacionou negativamente com a abordagem causation. Da mesma forma, com o passar dos anos, a habilidade cognitiva, o conhecimento e a segurança desenvolvida pelo empreendedor a frente do negócio podem influenciá-lo a adotar procedimentos menos causais e formais, como o estabelecimento de metas e planos e a realização de análises do ambiente. Estes resultados são condizentes com o estudo desenvolvido por Dew et al. (2009), que comparou o uso de informações prévias no processo empreendedor entre experts (empreendedores com grande experiência) e noviços (estudantes de MBA). Os experts dispensam ou ignoram as informações prévias, utilizando e confiando, em muitos casos, na sua própria intuição e na sua experiência pessoal para tomar decisões. O mesmo estudo identificou que os experts avaliam diferentemente os riscos e oportunidades, focando no que é possível gastar com os recursos disponíveis, enquanto os noviços buscam a maximização do investimento. Da mesma forma, Ucbasaran, Westhead e Wright (2009) constaram que até 4,5 negócios criados, há uma influência positiva da experiência anterior na identificação de oportunidades, mas acima disso não produziu efeitos. Para os autores, esse resultado pode significar que o esquema mental passa a ser reproduzido pela experiência e cessa o efeito sobre a identificação de novas oportunidades.

Sobre o nível de alerta empreendedor, este demonstrou uma relação linear positiva com ambas abordagens. Este achado indica que, quanto maior for o nível de alerta apresentado pelo indivíduo, maior a propensão dele em adotar práticas racionais e formais de planejamento e análise na exploração das oportunidades identificadas e avaliadas. Da mesma forma, maior será também o seu nível de flexibilização, que lhe permite experimentar práticas além das planejadas e oportunidades emergentes, o uso de pré-acordos com sua rede de relacionamento para adquirir novos meios ou reduzir incertezas e o cuidado para não comprometer recursos além de suas possibilidades. Esses achados evidenciam e reforçam a importância do conceito de alerta para o empreendedorismo.

O alerta está associado às duas abordagens, sendo que o que varia é a forma de explorar a oportunidade. Assim, o acesso e a busca deliberada por informação é importante não só para traçar planos e analisar o ambiente, mas também para encontrar novas oportunidades e novos meios. Da mesma forma, a capacidade cognitiva de associação e julgamento dessas informações, além de auxiliar na avaliação sobre a maximização do retorno dos investimentos, favorece a construção de esquemas mentais com recursos e meios disponíveis, sejam eles próprios ou da própria rede de relacionamento.

No entanto, mesmo que o nível de alerta consistiu em uma variável preditora positiva de ambas abordagens, a relação foi mais forte para a abordagem causation. Uma análise mais complexa indica a existência de uma relação não linear curvilínea no formato de um $\mathbf{U}$ invertido entre essas duas 
variáveis. Isso demonstra que, a partir de um determinado nível de alerta, a relação passa a ser inversa (negativa). Portanto, em um alto nível de alerta, o empreendedor passa a realizar menos planos e análises formais, provavelmente, devido à alta quantidade de informação armazenada ou pela experiência adquirida. Como evidenciado por este estudo e também pelo estudo de Dew et al. (2009), quanto maior a experiência, maior será o uso da intuição e dos meios disponíveis, portanto menor será o nível de adoção de processos causais.

O último resultado refere-se ao fato de as duas abordagens empreendedoras estudadas não serem opostas, sendo adotadas simultaneamente na condução dos negócios. Aliás, quando incluída ao modelo de regressão, a abordagem causation demonstrou maior poder de explicação para abordagem effectuation, do que o próprio grau de alerta. Portanto, a abordagem causal reforça a abordagem effectuation. Como já mencionado na revisão da literatura, a situação ou contexto podem influenciar a adoção de uma ou outra abordagem, podendo até mesmo serem combinadas para a conquista de melhores resultados, como também encontrado por Harms e Schiele (2012) ao estudarem a constituição de negócios internacionais.

Os resultados dessa pesquisa contribuem para ampliar o leque de variáveis como preditoras ou antecedentes das abordagens causation e effectuation introduzidas por Sarasvathy (2001). Novos estudos podem ser realizados buscando ampliar o entendimento dessa relação, incluindo possíveis variáveis moderadoras nesse efeito, como, por exemplo, características da organização iniciada e variáveis ambientais, como o grau de incerteza. Da mesma forma, por ter sido realizado com empresas pertencentes a associações comerciais, destaca-se o alto grau de heterogeneidade dos respondentes, predominantes do setor de comércio e serviços. Assim, sugere-se a realização de pesquisa semelhante em empresas do ramo industrial. Outra contribuição refere-se à validação das escalas desenvolvidas por Tang et al. (2012) e Chandler et al. (2011) em termos de confiabilidade. A adequação das mesmas se mostra importante para o desenvolvimento de outras pesquisas sobre o tema.

Uma das limitações do estudo é o corte transversal, sendo que estudos longitudinais poderiam fazer novas contribuições. Do mesmo modo, estudos qualitativos podem contribuir para desenvolver novos elementos para as abordagens causation e effectuation. Ademais, os resultados obtidos são válidos apenas para a amostra, limitando as generalizações.

\section{Referências}

Aidar, M. M. (2007). Empreendedorismo. São Paulo: Thomson Learning.

Ardichvili, A., Carodozo, R., \& Ray, S. (2003). A theory of entrepreneurial opportunity identification and development. Journal of Business Venturing, 18(1), 105-123. doi: 10.1016/S08839026(01)00068-4

Augier, M., \& Sarasvathy, S. D. (2004). Integration evolution, cognition and design: extending simonian perspectives to strategic organization. Strategic Organization, 2(2), 169-204. doi: $10.1177 / 1476127004042843$

Baron, A. R. (2006). Opportunity recognition as pattern recognition: how entrepreneurs "connect the dots" to identify new business opportunities. The Academy of Management Perspectives, 20(1), 104-119. Recuperado de http://www.jstor.org/stable/4166221. doi: 10.5465/AMP.2006.19873412

Baron, A. R. (2010). Opportunity recognition. In H. Landström \& F. T. Lohrke (Eds.), Historical foundation of entrepreneurship research (Cap. 6, pp. 121-141). Great Britain: Edward Elgar. 
Bezerra, F. A. (2012). Análise fatorial. In L. J. Corrar, E. Paulo, \& J. M. Dias Filho (Coords.), Análise multivariada: para os cursos de administração, ciências contábeis e economia (Cap. 2, pp.73130). São Paulo: Atlas.

Casson, M., \& Wadeson, N. (2007). The discovery of opportunities: extending the economic theory of the entrepreneur. Small Business Economics, 28(1), 285-300. doi: 10.1007/s11187-006-9037-7

Chandler, G. N., Detienne, D. R., Mckelvie, A., \& Mumford, T. V. (2011). Causation and effectuation processes: a validation study. Journal of Business Venturing, 26(1), 375-390. doi: 10.1016/j.jbusvent.2009.10.006

Dew, N., Read, S., Sarasvathy, S. D., \& Wiltbank, R. (2009). Effectual versus predictive logics in entrepreneurial decision-making: differences between experts and novices. Journal of Business Venturing, 24(1), 287-309. doi: 10.1016/j.jbusvent.2008.02.002

Fávero, L. P., Belfiore, P., Silva, F. L. da, \& Chan, B. L. (2009). Análise de dados: modelagem multivariada para tomada de decisões. Rio de Janeiro: Elsevier.

Filion, L. J. (1999). Empreendedorismo: empreendedores e proprietários-gerentes de pequenos negócios. Revista de Administração, 34(2), 5-28. Recuperado de http://www.rausp.usp.br/busca/artigo.asp?num_artigo=102

Fisher, G. (2012). Effectuation, causation, and bricolage: a behavioral comparison of emerging theories in entrepreneurship research. Entrepreneurship Theory and Practice, 36(5), 1019-1051. doi: $10.1111 / j .1540-6520.2012 .00537 . x$

Frese, M. (2009). Toward a psychology of entrepreneurship - An action theory perspective. Foundations and Trends in Entrepreneurship, 5(6), 437-496. doi: 10.1561/0300000028

Gartner, W. B. (1985). A conceptual framework for describing the phenomenon of new venture creation. The Academy of Management Review, 10(4), 696-706. Recuperado de http://www.jstor.org/stable/258039. doi: 10.2307/258039

Grégoire, D. A., Barr, P. S., \& Shepherd, D. A. (2010). Cognitive processes of opportunity recognition: the role of structural alignment. Organization Science, 21(2), 413-431. doi: $10.1287 /$ orsc. 1090.0462

Hair, J. F., Jr., Black, W. C., Babin, B. J., Anderson, R. E., \& Tatham, R. L. (2009). Análise multivariada de dados (6a ed.). Porto Alegre: Bookman.

Harms, R., \& Schiele, H. (2012). Antecedents and consequences of effectuation and causation in the international new venture creation process. Journal of International Entrepreneurship, 10(1), 95-116. doi: 10.1007/s10843-012-0089-2

Hébert, R. F., \& Link, A. N. (2006). Historical perspectives on the entrepreneur. Foundations and Trends in Entrepreneurship, 2(4), 261-408. doi: 10.1561/0300000008

Honig, B., \& Karlsson, T. (2004). Institutional forces and the written business plan. Journal of Management, 30(1), 29-48. doi: 10.1016/j.jm.2002.11.002

Kaish, S., \& Gilard, B. (1991). Characteristics of opportunities search of entrepreneurs versus executives: sources, interests, general alertness. Journal of Business Venturing, 6(1), 45-61. doi: 10.1016/0883-9026(91)90005-X

Kirzner, I. M. (1997). Entrepreneurial discovery and the competitive market process: an Austrian approach. Journal of Economic Literature, 35(1), 60-85. Recuperado de http://www.jstor.org/stable/2729693 
Lumpkin, G. T., \& Lichtenstein, B. B. (2005). The role of organizational learning in the opportunity recognition process. Entrepreneurship Theory and Practice, 29(4), 451-472. doi: 10.1111/j.1540-6520.2005.00093.x

Malhotra, N. (2001). Pesquisa de marketing: uma orientação aplicada (3a ed.). Porto Alegre: Bookman.

Marôco, J. (2010). Análise de equações estruturais: fundamentos teóricos, software \& aplicações. Pêro Pinheiro: ReportNumber.

McMullen, J. S., \& Shepherd, D. A. (2006). Entrepreneurial action and the role of uncertainty in the theory of the entrepreneur. The Academy of Management Review, 31(1), 132-152. Recuperado de http://amr.aom.org/content/31/1/132.abstract. doi: 10.5465/AMR.2006.19379628

Read, S., \& Sarasvathy, S. D. (2005). Knowing what to do and doing what you know: effectuation as a form of entrepreneurial expertise. The Journal of Private Equity, 9(1), 46-61. doi: 10.3905/jpe.2005.605370

Sarasvathy, S. D. (2001). Causation and effectuation: toward a theoretical shift from economic inevitability to entrepreneurial contingency. The Academy of Management Review, 26(2), 243263. Recuperado de http://www.jstor.org/stable/259121. doi: 10.5465/AMR.2001.4378020

Sarasvathy, S. D., \& Dew, N. (2005). New market creation through transformation. Journal of Evolutionary Economics, 15(1), 533-565. doi: 10.1007/s00191-005-0264-x

Sarasvathy, S. D., Dew, N., Velamuri, S. R., \& Venkataraman, S. (2010). Three views of entrepreneurial opportunity. In Z. J. Acs \& D. B. Audretsch (Eds.), Handbook of entrepreneurship research: an nterdisciplinary survey and introduction (Cap. 4, pp. 77-98). New York: Springer.

Schramm, C., \& Litan, R. (2008). The growth solution. The American Magazine. Recuperado de http://www.american.com/archive/2008/july-august-magazine-contents/the-growth-solution

Serviço Brasileiro de Apoio às Micro e Pequenas Empresas. (Org.). (2011). Anuário do trabalho na micro e pequena empresa: 2010-2011 (4a ed.). Brasília: DIEESE. Recuperado de http://bis.sebrae.com.br/GestorRepositorio/ARQUIVOS_CHRONUS/bds/bds.nsf/25BA39988A 7410D78325795D003E8172/\$File/NT00047276.pdf

Shane, S., \& Venktamaran, S. (2000). The promise of entrepreneurship as a field of research. The Academy of Management Review, 25(1), 217-226. Recuperado de http://www.jstor.org/stable/259271. doi: 10.5465/AMR.2000.2791611

Tang, J., Kacmar, K. M., \& Busenitz, L. (2012). Entrepreneurial alertness in the pursuit of new opportunities. Journal of Business Venturing, 27(1), 77-94. doi: 10.1016/j.jbusvent.2010.07.001

Ucbasaran, D., Westhead, P., \& Wright, M. (2009). The extent and nature of opportunity identification by experienced entrepreneurs. Journal of Business Venturing, 24(2), 99-115. doi: 10.1016/j.jbusvent.2008.01.008

Valliere, D. (2013). Towards a schematic theory of entrepreneurial alertness. Journal of Business Venturing, 28(1), 430-442. doi: 10.1016/j.jbusvent.2011.08.004 